\section{ANALISIS IMPLEMENTASI PROGRAM CORPORATE SOCIAL RESPONSIBILITY EDU VISIT PT GARUDA MAINTENANCE FACILITY AEROASIA, TBK}

\author{
${ }^{1}$ Sella Lovityo Aulia, ${ }^{2}$ Chrisentia Flavia Dwianjani, ${ }^{3}$ Rubiyanto \\ 1,2,3 Post Graduate Program, Institute Komunikasi dan Bisnis LSPR, Jakarta \\ Sella_lovityo@yahoo.co.id
}

Diterima : 21 Februarit 2020; Review : 18 juni 2020; Direvisi Author : 10 juli 2020; Terbit : 14 Agustus 2020

\begin{abstract}
PT Garuda Maintenance Facility, AeroAsia, Tbk (GMF) is a state-owned company, which is engaged in the aircraft maintenance and repair service industry in Indonesia, or Maintenance, Repair, and Overhaul abbreviated as MRO. One of the activities carried out by the company, namely Corporate Social Responsibility I CSR called 'Edu Visit'. Since 2002, Edu Visits have provided opportunities for the public, especially students and university student, who want to know about aerospace. Unfortunately, some Visitors, when participating in the Edu Visit, perceive it as a tourism activity, not a CSR program. The purpose of this study is to provide readers with an overview of the CSR program 'Edu Visit', the obstacles that occur and the solutions made by PT GMF. The method used is qualitative with a descriptive approach. The data were obtained through interviews with those involved in the Edu Visit, activity observation, and documentation. Researchers use legitimacy theory and the concept of CSR to analyze and answer research objectives. The results of the study can be explained that the Edu Visit activity conducted by PT GMF is an effective step for the company to gain public and environmental legitimacy. PT GMF uses communication to the public to overcome internal and external obstacles to the company. The method is to be more open and sustainable in conveying to the public about Edu Visit activities through direct communication, websites, and annual reports.
\end{abstract}

Keyword: Corporate Social Responsibility, Garuda Maintenance Facility, Legitimacy Theory

\section{PENDAHULUAN}

Aktivitas perusahaan yang terkait dengan Tanggung Jawab Sosial terhadap lingkungan sekitar atau dikenal dengan Corporate Social Responsibility / program $C S R$, merupakan suatu cara bagi perusahaan dalam membangun hubungan baik dengan masyarakat. Aktivitas saling menguntungkan antara perusahaan dan publik ini, tidak hanya diterapkan pada perusahaan swasta, namun program CSR juga wajib dilaksanakan bagi perusahaan 'plat merah', yang dikelola pemerintah.
Berdasarkan Undang - Undang Republik Indonesia Nomor. 40 tahun 2007, tentang Perseroan Terbatas, pada Bab V pasal 74, disebutkan bahwa: (1) Perseroan yang menjalankan aktivitas usahanya di bidang dan/atau berkaitan dengan sumber daya alam wajib melaksanakan Tanggung Jawab Sosial dan Lingkungan. (2) Tanggung Jawab Sosial dan Lingkungan sebagaimana dimaksud pada ayat 1, merupakan kewajiban perseroan yang dianggarkan 
dan diperhitungkan sebagai biaya Perseroan, yang pelaksanaannya dilakukan dengan memperhatikan kepatutan dan kewajaran. (3) Perseroan yang tidak melaksanakan kewajiban sebagaimana dimaksud pada ayat (1) dikenai sanksi sesuai dengan ketentuan peraturan perundang-undangan.

Ketentuan lebih lanjut mengenai Tanggung Jawab Sosial dan Lingkungan diatur dengan peraturan pemerintah (Undang-undang (UU) tentang Perseroan Terbatas, 2007).

Selanjutnya untuk lebih mengukuhkan bagaimana pengaturan program $C S R$, pemerintah mengeluarkan Peraturan Pemerintah Nomor 47 Tahun 2012 tentang Tanggung Jawab Sosial dan Lingkungan Perseroan Terbatas, yang intinya menyatakan bahwa, setiap perusahaan mempunyai tanggung jawab sosial dan lingkungan. Sedangkan dalam ISO 26000, CSR adalah bentuk kepedulian sosial perusahaan yang saat ini menjadi aspek penting dalam rangka meningkatkan kinerja perusahaan, di samping isu kualitas (ISO 9000) dan lingkungan (ISO 14000)" (Rachman, Efendi, \& Wicaksana, 2011).

Salah satu perusahaan milik pemerintah yang melakukan Program CSR, yaitu PT Garuda Maintenance Facility Aero Asia Tbk, yang merupakan perusahaan MRO (Maintenance Repair dan Overhaul) terbesar di Indonesia. Perusahaan ini memiliki salah satu program $C S R$, disingkat dengan GMF CSR, yang diberi nama Edu Visit. Program Edu Visit atau menerima kunjungan masyarakat luas ke dalam ruang lingkup aktivitas perusahaan, telah dijalankan GMF sejak tahun 2002. Program sosialisasi dan edukasi tentang industri penerbangan ini, telah dikunjungi oleh 12.949 siswa dan mahasiswa dengan jadwal rutin setiap hari Selasa dan Kamis (GMF CSR, n.d.).

Program Edu Visit yang sebelumnya bernama Public Visit ini, menurut Fariza Astriny selaku General Manager Corporate Communications CSR, bertujuan untuk memperkenalkan dan mengedukasi masyarakat tentang industri penerbangan. Termasuk keselamatan penerbangan, perawatan dan perbaikan pesawat secara berkelanjutan. Tujuannya agar para pelajar, mahasiswa, masyarakat luas mengetahui sejak dini salah satu profesi di industri penerbangan, yang dapat dipilih nantinya. (Astriny, 2019)

Ada beberapa program CSR yang lainnya yang dimiliki oleh perusahaan dalam bidang Pendidikan, Sosial dan keagamaan, yaitu program magang yang telah diikuti 1.228 siswa SMK \& 
Mahasiswa, 1.740 kantong darah yang berjalan lancar dan informasi yang disalurkan melalui PMI, 321 siswa \& diberikan pun benar dan efektif. Peserta Mahasiswa yang mendapatkan bantuan dana program akan diajak untuk melihat Pendidikan dan 3 fasilitas ibadah dibangun atau direnovasi.

Berdasarkan annual report 2019, GMF memberikan kesempatan kepada masyarakat untuk melakukan kunjungan publik. Setiap aktivitas kunjungan, para peserta akan didampingi oleh karyawan GMF, sehingga proses aktivitas dapat fasilitas hangar, proses kerja perawatan pesawat, berinteraksi dengan karyawan yang sedang melakukan pekerjaan, dan diperkenalkan dengan beragam profesi terkait dengan industri perawatan dan perbaikan pesawat, serta diberikan penjelasan ringan mengenai dunia perawatan pesawat terbang.

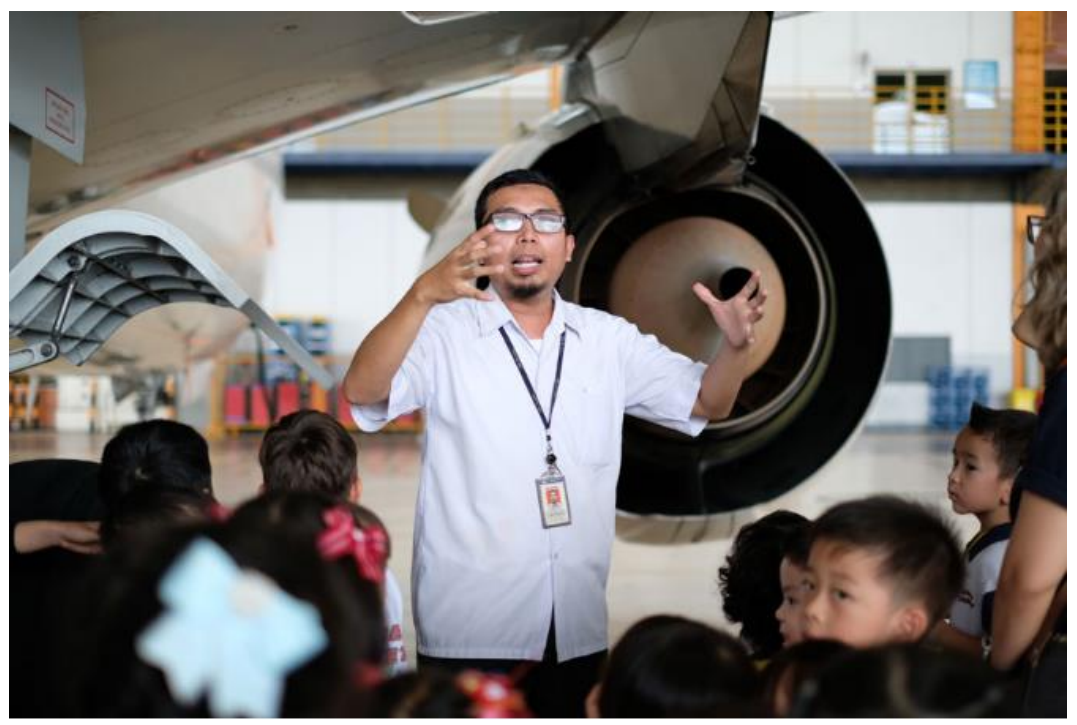

\section{Gambar 1. Kunjungan Siswa Sekolah Dasar di Program Edu Visit}

(Sumber: https://www.gmf-aeroasia.co.id/csr)

Pada gambar 1 memperlihatkan saat sejumlah pelajar Sekolah Dasar mengunjungi PT GMF dan mendapatkan penjelasan dari salah satu staff perusahaan.
Aktivitas Edu Visit yang dilakukan perusahaan ini, dalam rangka memperkuat profesi dan industri MRO, serta meningkatkan kesadaran tentang 
keselamatan penerbangan sejak dini. Sepanjang tahun 2019, Perseroan telah menerima kunjungan sebanyak 4.875 orang, dengan rincian 4.474 orang dari instansi pendidikan (TK, SD, SMP, SMA/SMK), dan 401 orang dari perguruan Ada beberapa hal aktivitas CSR yang dilakukan PT Garuda Maintenance Facility menarik untuk diteliti, yaitu pertama, perusahaan ini merupakan satusatunya anak perusahaan BUMN yang bergerak di bidang MRO (Maintenance, Repair, and Overhaul). Kedua, dibandingkan dengan pesaing perusahaan MRO yang berada di Indonesia, hanya PT Garuda Maintenance Facility Aero Asia Tbk yang memiliki program $C S R$ " $E d u$ Visit”, yang memperbolehkan masyarakat atau stakeholders mendapatkan edukasi melihat langsung ke dalam perusahaan MRO (Maintenance, Repair and Overhaul).

Sebagai satu-satunya perusahaan MRO yang memiliki program menerima kunjungan publik luar ke dalam perusahaan, aktivitas CSR Edu Visit ini tidak selalu berjalan mulus sesuai harapan. Masih banyak peserta beranggapan bahwa, berkunjung ke GMF untuk tujuan wisata bukan untuk menambah pengetahuan tentang dunia penerbangan. Mereka pun tinggi. Sementara pada tahun 2020, program ini ditiadakan sementara terkait pandemi Covid-19. (https://www.gmfaeroasia.co.id/csr/Education/Edu/vist/for/E ducational/institutions/en/)

seringkali protes terhadap aturan yang diberikan perusahaan, dan terkadang menggangu pekerjaan karyawan GMF lainnya di saat kunjungan.

Berdasarkan uraian tersebut, peneliti ingin menganalisis implementasi program CSR Edu Visit PT Garuda Maintenance Facility AeroAsia Tbk. Adapun tujuan penelitian ini, yaitu untuk memberi pemahaman tentang (1) program CSR Edu Visit PT Garuda Maintenance Facility AeroAsia Tbk, (2) untuk memahami kendala yang dihadapi dalam mengimplementasikan program CSR Edu Visit, dan solusi yang dilakukan PT Garuda Maintenance Facility AeroAsia Tbk.

Menurut (Smith \& Rhiney, 2020), istilah CSR dapat dikonseptualisasikan sebagai kumpulan dari berbagai domain, sub domain, dan perilaku yang menyoroti tanggung jawab yang ditujukan pada berbagai kelompok pemangku kepentingan. Archie Carroll (1991) menggambarkan payung CSR dalam empat 
bagian, yaitu tanggung jawab ekonomi, hukum, etika, dan filantropi. Matten dan

Tindakan eksplisit (Smith \& Rhiney, 2020) diklasifikasikan sebagai tindakan filantropi sukarela yang diarahkan kepada pemangku kepentingan internal atau eksternal untuk tujuan sosial atau penciptaan nilai bersama. Sedangkan CSR implisit adalah tindakan yang tampaknya dilakukan melalui aktivitas bisnis normal yang menciptakan nilai sosial seperti upah dan tunjangan yang tinggi bagi karyawan. Lebih lanjut, (Cornelius, Todres, Janjuha-Jivraj, Woods, \& Wallace, 2008) meneliti CSR dalam konteks CSR internal versus eksternal yang menunjukkan tindakan yang ditargetkan terhadap pemangku kepentingan berdasarkan hubungan mereka dengan perusahaan.

Lebih lanjut diuraikan Smith dan Rhiney (2020), CSR adalah kumpulan tanggung jawab yang dimiliki perusahaan terhadap masyarakat (Carroll, 1991). Ini mewakili upaya organisasi untuk meningkatkan kehidupan berbagai pemangku kepentingan atau menciptakan perubahan positif di lingkungan eksternal (Dahlsrud, 2008), atau cara yang digunakan perusahaan untuk mencari legitimasi sosial (Pollach, 2015).
Moon (2008) membagi CSR menjadi komponen "eksplisit" dan "implisit".

Legitimasi masyarakat merupakan faktor strategis bagi perusahaan dalam rangka mengembangkan perusahaan ke depan. Hal itu, dapat dijadikan sebagai wahana untuk mengkontribusikan strategi perusahaan, terutama terkait dengan upaya memosisikan diri di tengah lingkungan masyarakat yang semakin maju (Hadi, 2011).

Menurut O’Donovan (2002) (dalam Hadi, 2011, p. 88) dikatakan bahwa legitimasi organisasi dapat dilihat sebagai suatu yang diberikan masyarakat kepada perusahaan dan sesuatu yang diinginkan atau dicari perusahaan dari masyarakat. Dengan demikian, legitimasi merupakan manfaat atau sumberdaya potensial bagi perusahaan untuk bertahan hidup (Going Concern).

Sedangkan Deegan, Robin dan Tobin (2002) menyatakan legitimasi dapat diperoleh manakala terdapat kesesuaian antara keberadaan perusahaan tidak mengganggu atau sesuai (congruent) dengan eksistensi sistem nilai yang ada dalam masyarakat dan lingkungan. Ketika terjadi pergeseran yang menuju ketidak sesuaian, maka pada saat itu legitimasi 
perusahaan dapat terancam (dalam Hadi, 2011, p. 89).

Posisi legitimasi dan kesenjangan legitimasi antara perusahaan dan stakeholders menurut Gary O’Donovan (2002), dapat digambarkan sebagai berikut:

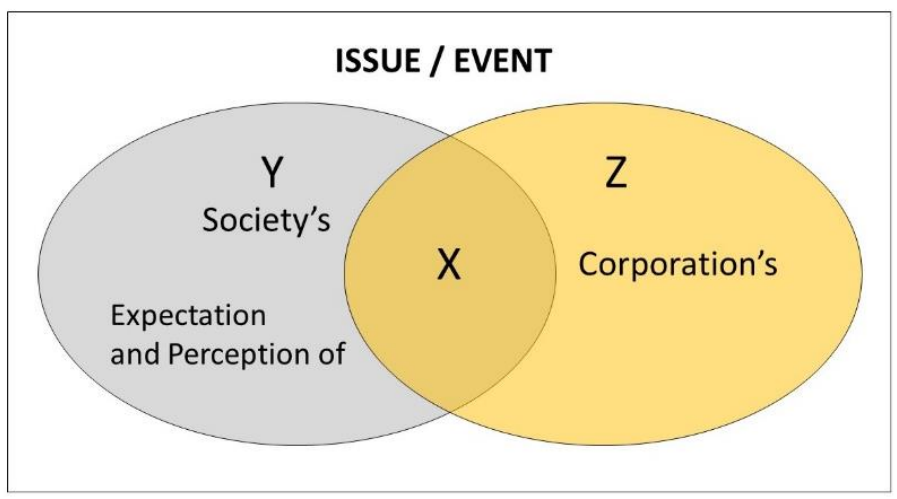

Gambar 2. Daerah Legitimacy Gap Gary O’ Donovan (2002) (dalam Hadi, 2011, p. 89)

Gambar di atas menunjukkan bahwa pengurangan kesenjangan legitimasi dapat dilakukan dengan jalan memperlebar wilayah $\mathrm{X}$ lewat strategi legitimasi, seperti dengan cara meningkatkan tanggung jawab Sosial (Social Responsibility) dan memperluas pengungkapan, termasuk pengungkapan sosial (Social disclosure) sebagai wujud akuntabilitas dan keterbukaan operasi perusahan, atas berbagai dampak yang ditimbulkan.

Pattern (1992) (dalam Hadi, 2011, p. 92) menyatakan upaya yang perlu dilakukan perusahan dalam mengelola legitimasi agar efektif, adalah dengan cara: (1) Melakukan identifikasi dan komunikasi / dialog dengan publik. (2) Melakukan komunikasi dialog tentang masalah nilai sosial kemasyarakatan dan lingkungan, serta membangun persepsi tentang perusahaan. (3) Melakukan strategi legitimasi dengan pengungkapan, terutama terkait dengan masalah tanggung jawab sosial (Social Responsibility).

\section{METODOLOGI PENELITIAN}

Metode penelitian yang digunakan dalam penelitian ini adalah kualitatif dengan pendekatan deskriptif, yaitu membuat deskripsi secara sistematis, faktual, dan akurat tentang fakta-fakta dan sifat-sifat populasi atau objek tertentu 
(Kriyantono, Teknis Praktis Riset Komunikasi, 2014)

Ada beberapa informan dalam penelitian (Suyanto, 2005) ini, antara lain: (1) Informan kunci (key informan), mereka yang mengetahui dan memiliki berbagai informasi pokok yang diperlukan dalam penelitian, yaitu: Fariza Astriny selaku General Manager Corporate Communicationsdan CSR. (2) Informan utama, mereka yang terlibat secara langsung dalam interaksi sosial yang diteliti, yaitu: Maulida Failasofa, selaku Corporate Communications Officer bagian CSR. (3) Kemudian Edwin Aldrian Santoso, mahasiswa Teknik Penerbangan Otto Lilienthal Institut Teknologi Bandung, dan (4) Ridwan Malik, Kepala Sekolah SDIT Al Muhajirin.

Selain itu Benny S. Butarbutar selaku Ketua Bidang Kerja Sama Strategis dari BPP Perhumas, yang sebelumnya pernah menjabat menjadi VP Corporate Communication Garuda Indonesia dan VP Corporate Commuication PT Citilink Indonesia.

Teknik pengumpulan data dalam penelitian ini adalah lebih banyak pada observasi berperan serta, wawancara mendalam, dan dokumentasi (Sugiyono,
2013). Keseluruhan data yang terkumpul, kemudian peneliti analisis melalui triangulasi sumber, yaitu data yang bersumber dari wawancara dengan beberapa informan, observasi saat program Edu Visit, dan beberapa dokumen, seperti annual report dan website GMF.

\section{HASIL DAN PEMBAHASAN}

PT Garuda Maintenance Facility AeroAsia, Tbk merupakan perusahaan MRO (Maintenance, Repair and Overhaul) terbesar di Indonesia, dan pada saat ini menduduki peringkat ke-12 di dunia. Perusahaan yang memiliki 4 (empat) hanggar pesawat dan salah satu merupakan hanggar terbesar di dunia, dan menjangkau lebih dari 180 customer yang tersebar di lima puluh negara pada lima benua. Atas prestasi dari kinerja perusahaan, PT GMF AeroAsia, Tbk berhasil mendapatkan sejumlah penghargaan dan safety and airowothiness certification dari sejumlah lembaga penerbangan di dunia.

Adapun layanan perawatan pesawat yang dapat diberikan oleh PT GMF AeroAsia, Tbk, meliputi Line Maintenance, Base Maintenance, Cabin Maintenance Services, Engine \& APU 
Maintenance, Component Services, Material \& Logistic Services, Engineering Services, Aircraft Support Services, Learning Services dan GMF Power Services. Kantor ini berlokasikan di Soekarno Hatta Airport Jl. GMF AeroAsia, Pajang, Benda, Kota Tangerang, Banten 15126, Indonesia.

Secara faktual, untuk merawat 1.500 pesawat di Indonesia, hanya 4 perusahaan MRO yang bisa dibilang kredibel. MRO yang sudah lama berdiri serta sudah mendapat sertifikasi dari FAA USA dan European Audit Safety Association (EASA) yakni GMF AeroAsia (GMF) yang memang sudah hampir 25 tahun berdiri.

Selain itu Lion air juga memiliki MRO di Batam, khusus untuk internal. Demikian juga Pelita air punya MRO di Pondok Cabe, melayani mayoritas armada Pelita Air, mayoritas Fokker 100 dan pesawat narrow body. Merpati Maintenance Facilities (MMF) di Surabaya masih bisa berkembang, khusus merawat Fokker 27, F 28, dan beberapa kliennya dari Filipina. MMF juga mempunyai sertifikasi dari Eropa.
GMF merawat pesawat Garuda Indonesia, beberapa maskapai asing juga telah mempercayakan perawatannya ke GMF, mulai dari yang ringan A check, $\mathrm{B}$ check, C check, sampai dengan D check. Pelanggan GMF di antaranya, yaitu Lion Air, Sriwijaya Air, KLM Belanda, Kabo Air Nigeria, PIA Pakistan, dan beberapa pesawat wide body kargo dari luar negeri. (Ridwan, 2018)

Sementara dalam struktur organisasi aktivitas CSR ditangani oleh sub divisi Corporate Communication \& CSR. Program CSR Edu Visit yang dilakukan GMF ini memiliki ketentuan atau prosedur, yaitu ditujukan untuk instansi pendidikan mulai dari Taman Kanak-Kanak hingga level Perguruan Tinggi, usia minimal peserta adalah 4 (empat) tahun, jumlah peserta maksimal yang mengikuti program ini adalah 50 orang, untuk peserta TK, SD, SMP, SMA/SMK. Sedangkan waktu pelaksanaannya setiap hari Selasa pada jam 09.00-11.00 dan untuk perguruan tinggi bisa diikuti setiap hari selasa pukul 09.00-12.00. Untuk Instansi pada hari Kamis pukul 09.00-15.00, khususnya lebih kepada benchmark sharing antar perusahaan mengenai tata kelola, manajemen resiko dan sebagainya. 
Untuk mengikuti kegiatan $E d u$ Visit, saat ini masyarakat dapat mendaftar langsung dengan mengirim surat atau email ke GMF. Berbeda dengan sebelumnya (Public Visit - nama awal), masyarakat bisa mendaftar langsung melalui formulir yang tersedia di website. Kebijakan ini dilakukan perusahaan, untuk memastikan bahwa yang mengikuti kegiatan ini adalah masyarakat, khususnya siswa atau mahasiswa, bukan para travel agent yang sering mengurus kegiatan wisata. Selain itu kebijakan diberlakukan mengingat kondisi pandemi covid-19, yang mewabah di seluruh negara, termasuk Indonesia.

Adapun bentuk formulir pendaftaran peserta yang tertera di website, sebagai berikut:

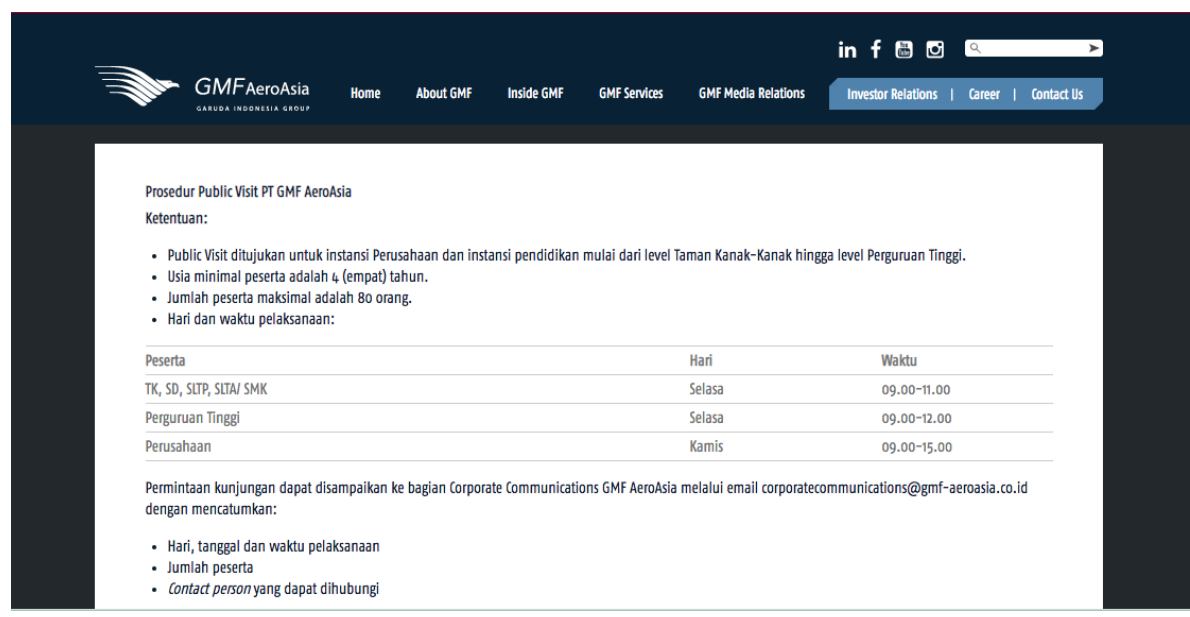

\section{Gambar 3. Formulir Pendaftaran Peserta Public Visit (Edu Visit)}

(Sumber: https://www.gmf-aeroasia.co.id/)

Dalam melakukan aktivitasnya, para peserta saat Edu Visit, diajak keliling perusahaan untuk melihat langsung mesinmesin yang digunakan pada pesawat beserta komponennya, serta penjelasan mengenai kedisiplinan, cara kerja, tata tertib, keamanan saat bekerja, keselamatan dalam pesawat terbang dan sebagainya.
Seperti dikatakan Fariza Astriny, ketika mereka diajak keliling, sekalian dijelaskan tentang GMF dengan cara bercerita (story telling), dan menjawab berbagai pertanyaan dari peserta secara langsung (Astriny, 2019). Sementara menurut Maulida Failasofa, gaya komunikasi saat menyampaikan cerita 
tersebut, disesuaikan dengan para peserta yang hadir saat itu (Failasofa, 2019).

Dari penjelasan keduanya dapat dipahami bahwa, GMF berupaya melakukan identifikasi peserta untuk berkomunikasi dengan baik kepada mereka. Hal ini bertujuan agar informasi yang diberikan dapat mudah dipahami, sehingga memberikan manfaat pengetahuan bagi para peserta. Seirama dengan upaya yang dilakukan perusahaan, Edwin mengatakan bahwa setelah berkunjung, ia mengetahui situasi kerja di GMF, apa saja hal-hal yang dilakukan, profil perusahaan, dan fasilitas-fasilitas yang ada di perusahaan. Menariknya, tambah Edwin, GMF juga memfasilitasi mahasiswa yang ingin mendalami di bidang perawatan pesawat terbang (Santoso, 2019).

Begitu pula yang dikatakan Ridwan Malik, program ini memiliki banyak manfaat yang diterima, baik untuk siswa ataupun guru, yaitu dapat menambah wawasan keilmuan secara langsung berkaitan dengan seluk beluk pesawat terbang. Selain itu lebih memantapkan minat siswa dalam hal karir dan cita-cita mereka untuk masa depan (Malik, 2019).

Uraian tersebut menggambarkan bahwa upaya yang dilakukan GMF mencerminkan efektivitas legitimasi seperti yang diutarakan Donovan, yaitu perlu dilakukan identifikasi peserta terlebih dahulu, sebelum berdialog dengan publik. Hasil dialog tersebut tentunya akan menumbuhkan persepsi mereka tentang aktivitas perusahaan dan membuka wawasan peserta terkait dengan kedirgantaraan.

Kesan baik peserta Edu Visit terhadap perusahaan, juga diperlihatkan GMF kepada mereka melalui budaya organisasi yang dimiliki. Seperti dikatakan Fariza Astriny, prosesnya diawali ketika mereka tiba di perusahaan, petugas security memberi penjelasan tentang safety regulation selama berkunjung. Selain itu petugas yang mendampingi peserta, juga harus ramah, dan memiliki kompetensi. Kompetensi ini tentunya diperoleh petugas tersebut dari pelatihan-pelatihan, yang diselenggarakan saat mengikuti seleksi untuk menjadi pendamping peserta (Astriny, 2019).

Menurut (Failasofa, 2019), sebagai perusahaan publik, GMF diwajibkan untuk membuat laporan tahunan terkait implementasi CSR Edu Visit. Selanjutnya sebagai bentuk akuntabilitas perusahaan, laporan tahunan dipublikasikan melalui website perusahaan, untuk diketahui 
publik. Terkait hal tersebut, menurut Benny, yang dilakukan GMF, sebagai perusahaan publik, ketika melakukan annual report, atau manly meeting, GMF sebaiknya menuangkan laporan tentang hambatan teknis, dan juga upaya-upaya yang dilakukan dalam keadaan krisis. Dengan demikian bisa memunculkan sebuah transparency, acountability dan sustainability, di bidang lingkungan, pendidikan dan kesehatan, yang dapat diketahui oleh masyarakat atau stakeholder lainnya." (Butarbutar, 2019)

Senada dengan Benny, Fariza Astriny mengatakan bahwa, "sebagai perusahaan terbuka kita melakukan Rapat Umum Pemegang Saham (RUPS) setiap tahun, dan wajib kita laporkan segala ativitas perusahaan termasuk program CSR. Jadi otomatis para pemegang saham tahu, sebagai bentuk annual report yang bekelanjutan untuk dipublikasikan ke publik." (Astriny, 2019)

Menurut peneliti, upaya akhir yang dilakukan GMF ini, merupakan suatu bentuk strategi legitimasi dengan

Namun, ketika peneliti mengamati website tidak menemukan tentang aturan terkait Edu Visit tersebut, hal ini dikarenakan kebijakan perusahaan yang meniadakan kunjungan untuk sementara pengungkapan kepada publiknya. Sehingga tidak hanya sekadar keterbukaaan informasi tentang kegiatan ini, akan tetapi berdampak pada meningkatnya citra baik perusahaan di mata publik dan atau stakeholder lainnya.

Adapun kendala yang dihadapi GMF saat kegiatan Edu Visit, baik eksternal (protes peserta tentang aturan perusahaan) atau internal (protes karyawan tentang terganggunya kerja mereka oleh peserta), solusi yang dilakukan perusahaan melalui dua acara:

Pertama, kendala eksternal, sebelum mereka berkunjung, tim yang menangani CSR menjelaskan ketentuanketentuan yang harus ditaati peserta, agar mereka memahami dan maklum terhadap standar operasional perusahaan yang ketat. Penjelasan tentang aturan-aturan tersebut termuat pada website, sehingga mereka sudah terinfokan tentang hal tersebut. Selain itu, ketika waktunya mereka datang ke perusahaan, para petugas juga menjelaskan kembali tentang aturan tersebut.

waktu di tahun 2020 sampai hilangnya pandemi covid-19. Akan tetapi, sebelum pandemi, proses mengajukan kunjungan ke GMF terdapat di laman pertama (home), dan tersedia kolom isian terkait aturan- 
aturan yang harus dipahami calon peserta tersebut (gambar 2). Sedangkan aktivitas CSR lainnya, dapat dijumpai di laman lainnya

Kedua, kendala internal, solusi yang diambil tim CSR, yaitu melakukan komunikasi langsung kepada bagian atau divisi yang akan dikunjungi. Hal tersebut dilakukan tim untuk mendapatkan persetujuan karyawan lain, agar tidak menggangu pekerjaan mereka, dan bahkan siap membantu untuk melayani peserta kunjungan.

\section{PENUTUP}

PT GMF AeroAsia, Tbk, merupakan perusahaan publik di bidang MRO ini, dalam menjalankan ativitas Corporate Social Responsibility / CSR melalui Edu Visit, telah mengefektifkan legitimasi perusahaan. Caranya yaitu: pertama, meningkatkan pelayanan kepada publik, melalui informasi di website terkait program Edu Visit. Kedua, gaya penyampaian pesan diseuaikan dengan profil peserta. Identifikasi peserta dilakukan saat mereka melakukan registrasi. Ketiga, ketika peserta datang ke GMF, para petugas dibekali dengan pemahaman budaya organisasi, dan kompetensi. Keempat, setelah aktivitas berlangsung, melakukan evaluasi dengan membuat laporan kinerja $C S R$ kepada masyarakat dan stakeholder, yang dituangkan ke dalam annual report secara berkelanjutan di website perusahaan.

Dari uraian tersebut, dapat dipahami bahwa pentingnya komunikasi bagi sebuah perusahaan, untuk membangun hubungan baik antara perusahaan dengan publiknya, baik ekternal ataupun internal. Sehingga hal tersebut akan mengarah terciptanya citra perusahaan yang lebih baik lagi.

Mengingat aktivitas CSR yang dilakukan oleh PT Garuda Maintenance Facility, AeroAsia, Tbk (GMF) melalui Edu Visit ini sudah berlangsung lama. Maka peneliti menyarankan agar dibuat terobosan baru, untuk menghindari kebosanan bagi para petugas yang mengurusi program $C S R$ ini, misalnya dari sisi internal, perusahaan dapat merotasi karyawan yang menangani kegiatan tersebut, dan meningkatkan koordinasi kepada divisi lain agar tidak lagi terjadi komplain internal. Sedangkan dari sisi eksternal, perusahaan dapat menyediakan kolom chat pada tampilan website, sebagai media perantara antara perusahaan dan masyarakat yang ingin mengikuti $E d u$ Visit. 
Akhirnya, diharapkan melalui program CSR Edu Visit ini, sebagai sebuah perusahaan yang bergerak di industri Maintenance, Repair, and Overhaul atau MRO, GMF akan memiliki program

\section{DAFTAR PUSTAKA}

Astriny, F. (2019, Mei). General Manager Corporate Communications dan CSR.

Butarbutar, B. S. (2019, Juni 07). Ketua Bidang Kerja Sama Strategis dari BPP Perhumas.

Failasofa, M. (2019, Mei 02). Corporate Communication \& CSR Officer .

GMF CSR. (n.d.). Retrieved from https://www.gmfaeroasia.co.id/csr?year=2019-01

Hadi, N. (2011). Corporate Social Responsibility. Yogyakarta : Graha Ilmu.

Kriyantono, R. (2014). Teknis Praktis Riset Komunikasi. Jakarta: Kencana Prenadamedia Group.

Malik, R. (2019, Mei 05). Kepala Sekolah SDIT Al Muhajirin.

Rachman, M. N., Efendi, A., \& Wicaksana, E. (2011). Panduan unggulan dalam berkompetisi (competitive advantage). Adapun keuntungan lainnya, yang dapat diraih GMF, yaitu meningkatnya citra perusahaan di mata publik dan stakeholder lainnya.
Lengkap Perencanaan CSR. Jakarta: Penebar Swadaya. Ridwan. (2018, Februari 18). Raih Untung Besar, Inilah Empat Perusahaan yang Konsisten Bisnis MRO di Indonesia. Retrieved from https://www.industry.co.id/read/26 $135 /$.

Santoso, E. A. (2019, mei 25). Mahasiswa Teknik Penerbangan Otto Lilienthal Institut Teknologi Bandung.

Smith, D., \& Rhiney, E. (2020). CSR commitments, perceptions of hypocrisy, and recovery. International Journal of Corporate Social Responsibility, 1-12. doi:10.1186/s40991-019-0046-7

Sugiyono. (2013). Metode Penelitian Kuantitatif Kualitatif Dan $R \& D$. Bandung: Alfabeta. 
Commed : Jurnal Komunikasi dan Media Vol. 5 No. 1 Agustus 2020 ISSN. 2527-8673

Suyanto, S. (2005). Dasar-dasar

Pendidikan Anak Usia Dini.

Yogyakarta: Hikayat.

Undang-undang (UU) tentang Perseroan

Terbatas. (2007, Agustus 16).

Retrieved from https://www.ojk.go.id/:

https://peraturan.bpk.go.id/Home/D

etails/39965 